\title{
FROM PRACTICE TO COLLABORATIVE COMMUNITY IN INTERDISCIPLINARY RESEARCH CONTEXTS
}

\author{
Frank Siedlok ${ }^{\mathrm{a}}$, Paul Hibbert ${ }^{\mathrm{b}}$, John Sillince $^{\mathrm{c}}$ \\ ${ }^{a}$ University of Auckland Business School, Owen G Glenn Building; 12 Grafton Road, 1010 Auckland, New \\ Zealand. \\ Phone: +64 9 3737599, ext. 82744. Email: f.siedlok@auckland.ac.nz \\ corresponding author
}

${ }^{\mathrm{b}}$ School of Management, University of St Andrews, St Andrews, Fife, UK

${ }^{c}$ Newcastle University Business School, Newcastle upon Tyne, UK 


\begin{abstract}
This paper contributes to the debate on the dynamics of the development of practices and their relation to the emergence of collaborative communities of practitioners. Our research is situated in a university that was seeking to promote and stimulate interdisciplinary research collaborations through a number of initiatives. We are concerned both with characterizing the practices that make this kind of collaboration possible, and with the emergence of a community that creates and endorses such collaborative practices. Our findings provide insights in relation to two particular questions. First, we report on the development of interdisciplinary practices and the emergence of community. Second, we consider how support interventions undertaken by the university stimulated the development of those practices. We develop theoretical and practical insights in these areas.
\end{abstract}

Keywords: practice, community of practice; interdisciplinary research; 


\section{FROM PRACTICE TO COLLABORATIVE COMMUNITY IN INTERDISCIPLINARY \\ RESEARCH CONTEXTS}

\section{Introduction}

Work within contemporary organizations is increasingly enacted by interdisciplinary teams (Blackler and Regan, 2009; Czarniawska, 2004; Lindkvist, 2005; Nicolini et al., 2012). This is because collaboration across knowledge domains is recognized as a source of competitive advantage (Liedtka, 1999; Scarbrough and Swan, 2008) and a response to the complex demands of the modern world (Aram, 2004; Buanes and Jentoft, 2009; Huutoniemi et al., 2010; König et al., 2013; van Rijnsoever and Hessels, 2011). Nevertheless a gap exists in our knowledge of how such collaborations are accomplished and the kinds of emergent organizational forms in which it occurs. We shall argue that such collaborations are underpinned by specific practices that lead to development of collaborative communities, and that this pattern of emergence can be supported by a range of initiatives. To demonstrate this, we take a Communities of Practice (CoP hereafter) perspective on the issue.

Both academic disciplines and professional groups within organizations have previously been conceptualized as CoPs in studies on knowledge development and sharing within and across such groups (e.g. see Becher and Trowler, 1989; Ferlie et al., 2005). While originally the CoP framework provided a useful explanation of situated learning through socialization and legitimate peripheral participation (Brown and Duguid, 2001; Lave and Wenger, 1991), recent research has substantially extended the range and scope of practice-based studies (Blackler and Regan, 2009; Gherardi, 2009a; Miettinen et al., 2009; Nicolini, 2009). Despite the possible over-generalization of CoP theories that could result (Amin and Roberts, 2008; Handley et al., 2006), we argue that this 'lens' provides a useful framework to explain the dynamics of the co-emergence of practices and communities within collaborative contexts.

CoP concepts help to illuminate how resources for organizing are marshalled and how participants make sense of their collective contexts (c.f. Brown and Duguid, 1991; Lave and Wenger, 1991; 
Wenger, 1998). In particular: communities are understood to provide the resources for organizing that support the 'foundings and failures of organizational forms' (Freeman and Audia, 2006, p. 145); and practices have been associated with the reproduction of organizational forms and sense-making within them (Bjørkeng et al., 2009; Gherardi, 2009b). But what supports sense-making in one community context produces confusion in another. Thus, while collaboration between communities can advance learning and innovation, differences between the practices of communities seeking to collaborate have been described as obstructing these outcomes (Duguid, 2005; Ferlie et al., 2005; Gertler, 2008; Nooteboom, 2008). Hence, understanding the dynamics and tensions underlying the development of new, shared practices that surmount barriers to learning and innovation in collaborative contexts is important. However, most studies of practice to date have focused largely on single, and usually preexisting, communities and thus provide limited insight into what happens at the intersection of interacting communities.

Studies that have addressed inter-community engagements either focused on the use of boundary objects (Carlile, 2002; Sapsed and Salter, 2004; Wenger, 2000; see also Nicolini et al., 2012 for discussion on the use of boundary, epistemic and activity objects) or presumed that inter-CoP interactions are transient and purely project related (Blackler and Regan, 2009; Czarniawska, 2004; Ferlie et al., 2005; Lindkvist, 2005). For example, König et al (2013, p. 266) suggest that the development of more enduring forms of organization is hindered by difficulties in maintaining an 'interdisciplinary culture'. These difficulties can partly be explained by the 'tribal' affiliations of researchers who resist abandoning their own disciplinary perspective resulting from years of commitment and experience (Ferlie et al., 2005; Gooch, 2005). Indeed, it can be argued that sustainable interdisciplinary engagements can be inhibited by commitments to existing practices and communities (c.f. Nicolini et al., 2012). These commitments lead to high levels of specialization in disciplinary CoPs and fragmented and only nominally 'interdisciplinary' research fields where genuine collaboration might otherwise exist (Morlacchi and Martin, 2009, p. 577; see also Martin, 2011). 
Thus there is a need to understand how multiple disciplinary and professional groups may overcome the difficulties alluded to above, and how they develop collective capabilities and a sense of 'meta'community that can enable collaborative working in a sustainable manner (Engeström, 2006, 2005; Lyall and Meagher, 2012; Ynalvez and Shrum, 2009, p. 827). The (rather limited) evidence suggests that, first, collaborative engagements between established, epistemically dissimilar, communities are enabled by the development of shared (interdisciplinary) practices among participants and, second, may depend on the provision of appropriate long-term support (e.g. see Olsen, 2009; Palmer, 1999). These are the two key concerns of our research, leading to two main areas of contribution. First, we contribute to debate on the development of practices and the emergence of collaborative communities. Through research situated in an interdisciplinary research (IDR hereafter) context, we characterize three distinct sets of collaborative practices and describe how these practices contribute to the emergence and the endurance of collaborative community. Second, we consider the role of support interventions in facilitating the development of the collaborative practices that support community development. The remainder of this paper proceeds as follows. We begin by discussing the relevant literature on the emergence of practices and communities, with focus on IDR and the formation of interdisciplinary communities. We then provide methodological details and report our findings. The paper ends with discussion and conclusions, which provide insights for theory and may inform the design of future programs to support the development of collaborative practices.

\section{Practices, communities and collaborations}

The extant literature suggests a chicken-and-egg relationship between the collectivity that forms at the boundary between established organizational structures in collaboration and the practices through which this boundary-spanning collectivity is coordinated (Kellogg, 2011; O'Mahony and Bechky, 2008). Thus the dynamics of the emergence of practices and community is still an important matter of debate that requires further attention. In line with our research objectives, we first discuss the issue of emergence of practices and communities, focusing on IDR, followed by a brief discussion on how the emergence of collaborative practices can be facilitated. 


\subsection{From practices to communities: the case of IDR}

The majority of the extant literature is based on research situated either within pre-existing communities of practice or within pre-arranged forms of inter-community collaboration (Bjørkeng et al., 2009; Gherardi, 2009a; Lave and Wenger, 1991; Olsen, 2009), suggesting that the existence of some stable social structure has been assumed to be necessary for the maintenance or development of practices (Bjørkeng et al., 2009; Gherardi, 2009b). Consequently, there is little insight into the dynamics of the emergence of practices and communities when there is no pre-established community or project group. This means that there has also been no clear articulation of how (if at all) new, stable communities may arise from collaborations between different groups.

However, the literature has some potentially transferable insights about collaboration between communities. Perhaps the most useful insights come from research where disciplines or other professional groups (e.g. see Ferlie et al., 2005) have been conceptualized from the CoP perspective. As CoPs, disciplines are constituted by systems of social relationships and practices, which are developed through apprenticeship and participation (Lattuca, 2002; Lave and Wenger, 1991), and are cultural entities that shape the behaviours, systems of values and worldviews of their members (Buanes and Jentoft, 2009; Klein, 1990; Weingart and Stehr, 2000). These characteristics are distinctive differences that are particularly visible (and problematic) in collaborative contexts (Aram, 2004; Becher and Trowler, 1989; Haas and Park, 2010; Scarbrough and Swan, 2008). IDR, a context in which different disciplines work together despite such differences, can therefore provide a useful setting for the investigation of inter-community collaboration (e.g. see Jamali and Nicholas, 2010; Olsen, 2009).

Literature suggests that IDR (and other inter-CoP) collaborations are difficult to achieve and that they dissolve when organizational circumstances change (Lindkvist, 2005; Raasch et al., 2013). Such studies imply that stability is rarely achieved (Nicolini, 2011), making this form of collaboration difficult to sustain. Partly difficulties are associated with the differences between the practices and systems of values endorsed by different disciplines (see Dougherty, 1992; Ferlie et al., 2005; 
Finkenthal, 2001; Scarbrough and Swan, 2008). While some authors suggest that the creation and maintenance of an interdisciplinary culture is therefore crucial for success in interdisciplinary collaborative projects (König et al., 2013; Pickett et al., 1999), the concept of 'interdisciplinary culture' shared among IDR participants remains vague. An alternative focus, on the necessary learning processes that need to take place for individuals to be able to successfully pursue IDR, has sidestepped the culture issue (Lattuca, 2002; Lyall and Meagher, 2012) through focussing on IDR-specific skills (Jeffrey, 2003; Klein, 1990; Welsh et al., 2006) and practices (Jamali and Nicholas, 2010; Olsen, 2009).

It has also been suggested that transformations associated with new, distinct collaborative norms could be transmitted through the socialization systems of collaborative communities (Adler et al., 2008; Olsen, 2009) and that practices are involved in the generation of community (Bjørkeng et al., 2009; Gherardi, 2009a, 2009b; Nicolini, 2011). But this brings us to the chicken-and-egg relationship of practice and community, since emergent collaborative practices do not 'belong' to any pre-existing stable community. This suggests that successful IDR collaborations are reliant on the emergence of specific practices, and that these practices are somehow recognized by participants as being of value without the legitimating authority of a stable community. But this does not avoid the implication that enduring IDR collaborations involve the formation of a community that endorses such practices. Thus the first focus of our research is concerned with what constitutes the collaborative 'practices of community' (c.f. Gherardi, 2009a, p. 121): what they might be, how they are manifested and how they might potentiate the emergence of a stable community. This also leads to a concern with how the emergence of collaborative practices (and the enduring communities that depend on them) might be facilitated by appropriate support initiatives.

\subsection{The need to facilitate the development of collaborative practices}

There have been increasing organizational pressures to support the development of more collaboration between disciplines and professions (Adler and Heckscher, 2006; Adler et al., 2008; Lyall and Meagher, 2012), and in particular an increasing number of initiatives to promote the development of 
IDR across universities (Khapova and Arthur, 2011). This trend is perhaps unsurprising as complex socio-environmental and technological problems, resolvable only with expertise from multiple fields, continue to emerge (Jeffrey, 2003; Lawrence and Després, 2004; Szostak, 2007). However, despite the growing prominence of IDR, many of the approaches to supporting it remain based on imprecise and inconsistent conceptualizations of what it might be (Siedlok and Hibbert, 2014). Consequently, despite the recognition that IDR might depend on developing new skills (Lattuca, 2002) and the emergence of new practices, perceptions and attitudes towards collaborative work-based communities (see Nooteboom, 2008; Olsen, 2009; Scarbrough and Swan, 2008; Siedlok and Hibbert, 2014), practitioners and researchers often remain over-focused on the structural aspects of such collaborations. These include, for example, the physical aspects of the 'community' (Gherardi, 2009a), resulting in new organisational arrangements ${ }^{1}$, policies and funding (e.g. see Stokols et al., 2012). Indeed, imposing a certain organizational form is often assumed to be the most important factor for enabling the facilitation and cultivation of collaborative communities (Cox, 2005, p. 538; Kirkman et al., 2013; Thompson and Walshmam, 2009; Wenger et al., 2002). In practice this has resulted in the development of new 'top-down' structural designs for, and definitions of, communities ${ }^{2}-$ many of which have been argued to over-stretch the CoP concept (Amin and Roberts, 2008, p. 355; Lindkvist, 2005; Roberts, 2006).

In contrast, the complex 'bottom-up' constitutive relationship between practices and communities has been rather neglected (Gherardi, 2009a). Thus, despite becoming increasingly important for knowledge creation, the dynamics of IDR remain poorly understood (Duncker, 2001; Huutoniemi et al., 2010) and interventions intended to promote and develop IDR are somewhat hit-and-miss. In this research, we infer that supporting IDR effectively in the long term requires interventions that potentiate the development of specific practices that support for the formation of communities. Thus,

\footnotetext{
${ }_{1}^{1}$ e.g. numerous interdisciplinary centres for advanced studies

2 Some of the examples include: 'oCoPs = organizational communities of practice'(Kirkman et al., 2013), 'VCoPs = virtual communities of practice'(Dubé et al., 2005, 2003), 'networks of practice'(Brown and Duguid, 2001), 'ClM = collectivities of practice' (Lindkvist, 2005). See also Thompson and Walsham (2009, p. 3).
} 
we are concerned with the potential role of deliberate interventions in stimulating the development of such practices. We offer our results after first presenting the methodology for this investigation.

\section{Methodology}

\subsection{Research approach}

Our approach to this research was partial ethnography, defined by Alvesson and Deetz (2000) as a process that follows the principles of ethnographic research but which, although it uses the same data gathering methods of participant observation and interviews, is applied to a narrower context within an organizational setting (c.f. Rosen, 2007). Data collection was centred around author 1's position as a participant observer. While contributing to general discussions in the program he did not participate in specific research projects, but was identified to participants as a researcher. Thus author 1's role was weighted towards the observer end of the spectrum, but with a sufficient degree of participation such that he could have an 'insider's feel' for the data. Author 2 was involved in some BTG program discussions but was not involved in data collection. Author 3 had no contact with the BTG program and provided a balancing, relatively detached, 'outsider' perspective.

Our study was concerned with the context of processes and interactions within the 'Bridging The Gap' (BTG) initiative at a UK university, rather than the 'whole life' of university members. Originally the BTG initiative, supported by 3 years of external funding ${ }^{3}$, was to 'to stimulate collaboration across the full range of Engineering, ICT and Mathematics, Statistics and Operations Research (Management Science) Departments'. More specifically, the program's main objectives were to create infrastructure for funding and exchanging expertise; to provide opportunities for confidence building; to generate sustainable collaborations; and to learn at institutional level how collaborations can be effectively built. As the initiative progressed additional internal funding was offered in order to, first, broaden the initiatives to other faculties (including social sciences) and, second, to continue the programme beyond the initial 3 years.

\footnotetext{
${ }^{3}$ The project was funded by the Engineering and Physical Sciences Research Council, UK. While number of the UK institutions were recipients of the funding, their goals and approaches differed significantly.
} 
The BTG programme was designed around a number of interventions, detailed in Table 1. Overall, the program was organised through a BTG steering group (comprised of researchers from several contributing disciplines). Facilitation of large-scale and/or general interventions (e.g. university research day, speed networking) was provided by members of the steering group. Processes in particular focussed interventions (e.g. themed workshops and seminars, sandpits) were facilitated by the researchers who had proposed and developed the area of focus. For all activities an appointed administrator (part of BTG team) provided practical support and managed logistics (such as the arrangement of workshop space, arrangements for catering, administering travel and other funding lines).

Table 1

Overview of the main BTG initiatives

\begin{tabular}{|l|l|}
\hline Intervention & Description \\
\hline $\begin{array}{l}\text { University } \\
\text { Research Day }\end{array}$ & $\begin{array}{l}\text { University-wide poster-conference during which participants present their } \\
\text { research to interdisciplinary audience. Posters and presentations were judged by } \\
\text { a cross-disciplinary panel. }\end{array}$ \\
\hline $\begin{array}{l}\text { Themed } \\
\text { workshops and } \\
\text { seminars }\end{array}$ & $\begin{array}{l}\text { Series of seminars or problem-focused workshops around specific themes } \\
\text { proposed by researchers. These were free to attend for anyone interested in the } \\
\text { subject, with the main goal to explore specific themes for potential } \\
\text { interdisciplinary research collaborations. }\end{array}$ \\
\hline $\begin{array}{l}\text { Speed dating } \\
\text { (networking) }\end{array}$ & $\begin{array}{l}\text { Short, managed networking meetings in which participants discuss their research } \\
\text { with all other participants in limited time. }\end{array}$ \\
\hline Sandpits & $\begin{array}{l}\text { 1.5 day events in which cross-disciplinary teams developed proposals around a } \\
\text { particular theme to compete for research funding. }\end{array}$ \\
\hline Short projects & $\begin{array}{l}\text { Short cross-disciplinary projects funded by the BTG initiative to investigate and } \\
\text { develop ideas into research proposals. }\end{array}$ \\
\hline $\begin{array}{l}\text { Visiting } \\
\text { professors }\end{array}$ & $\begin{array}{l}\text { A number of visiting professors were invited to engage with cross-disciplinary } \\
\text { teams through participating in cross-disciplinary seminars or sandpits. }\end{array}$ \\
\hline $\begin{array}{l}\text { New joiner } \\
\text { meetings }\end{array}$ & $\begin{array}{l}\text { Networking event for new members of staff in which teams developed cross- } \\
\text { disciplinary ideas and competed for further funding to develop these ideas. }\end{array}$ \\
\hline $\begin{array}{l}\text { Function related } \\
\text { meetings }\end{array}$ & $\begin{array}{l}\text { A series of cross-departmental meetings aimed at individuals holding a similar, } \\
\text { and research-related, function (e.g. research seminar organizers) to explore if } \\
\text { collaboration at this level would promote IDR engagements. }\end{array}$ \\
\hline $\begin{array}{l}\text { Dragons Den- } \\
\text { style competitions }\end{array}$ & $\begin{array}{l}\text { Competition in which cross-disciplinary ideas were pitched for funding during } \\
\text { the URD. }\end{array}$ \\
\hline
\end{tabular}

An extended version of the BTG approach (no longer) continues to this day. It is no longer externally funded and is supported through collaborative contributions, since there were no formal structural 
changes to the organization of the University associated with the design, implementation or outcomes of the BTG program.

\subsection{Data collection}

The majority of our data was collected between 2007-2010, during the initial period of the BTG initiative, with additional data collection in 2013. Consequently, we base our findings on two datasets, which we refer to as the 'initial' and 'follow-up'. Details related to the data collected are presented in

Table 2. From the beginning we have adopted an open-ended inductive stance (Berg and Lune, 2004;

Sapsed and Salter, 2004) in our research, but have included a breadth of data gathering approaches.

Table 2

Details of the data used in the study

\begin{tabular}{|c|c|}
\hline Type of data & Details \\
\hline $\begin{array}{l}\text { Observations } \\
\text { (events) } \\
\text { 2007-2010 }\end{array}$ & \begin{tabular}{|cl}
$\mathbf{5 2}$ & different events in total, including: \\
$\mathbf{8}$ & non-recurring / short events (between $1.5 \mathrm{~h}$ and $4 \mathrm{~h})$ \\
$\mathbf{1 5}$ & recurring / long events \\
4 & long events $(1 \mathrm{x} 2$ days event; $3 \mathrm{x} 1$ day events) \\
3 & project groups: 11 meetings in total $(5 / 5 / 3$ meetings between $(1.5-3 \mathrm{~h}$ each) \\
$\mathbf{2 6}$ & BTG board or other management related meetings \\
12 & BTG board: regular meetings $(1-2.5 \mathrm{~h})$ \\
2 & BTG Board special meetings $(1-2 \mathrm{~h})$ \\
5 & Champions meeting $(2-3 \mathrm{~h})$ \\
3 & BTG management related meetings $(1.5-3 \mathrm{~h})$ \\
2 & BTG groups meetings $(1.5-3 \mathrm{~h})$ \\
2 & EPSRC representative meetings $(2-3 \mathrm{~h})$ \\
$\mathbf{3}$ & non-BTG related events (collaborative meetings) $(1.5-3 \mathrm{~h})$ \\
\end{tabular} \\
\hline $\begin{array}{l}\text { Interviews } \\
\text { 2007-2010 }\end{array}$ & $\begin{array}{l}\text { Initial data collection: } \\
\text { interviews } \\
46 \text { formal interviews (ranging between } 30-120 \text {, average } 80 \text { minutes) } \\
1 \text { informal / unplanned interviews ( } 90 \text { minutes) } \\
7 \text { short interviews during one of the University-wide events (between } 10-15 \\
\text { minutes) }\end{array}$ \\
\hline 2013 & $\begin{array}{l}\text { Follow-up data collection: } \\
8 \text { interviews } \\
7 \text { formal interviews with participants in BTG initiatives (ranging between } 45 \text { - } \\
100 \text { minutes) } \\
1 \text { formal interview with } 3 \text { BTG administrative staff members. }\end{array}$ \\
\hline $\begin{array}{l}\text { Other sources } \\
\text { of data } \\
\text { 2007-2010 }\end{array}$ & $\begin{array}{l}\text { Electronic communication; meetings minutes and other relevant documents } \\
\text { Emails: in total some 987; out of which } 144 \text { email threads had direct relevance, and } \\
67 \text { email threads were used directly in the coding process (included as data in } \\
\text { NVivo). } \\
\text { Minutes and other relevant documents: } 105 \text { documents were used directly in the } \\
\text { coding and theorizing process (included as data in NVivo) }\end{array}$ \\
\hline 2013 & Follow-up questionnaire among BTG participants \\
\hline
\end{tabular}


59 responses in total, from staff who had participated in at least one BTG initiative. The mailing list used (110 participants) does not necessarily correspond to all participants due to inevitable staff moves across a six-year research period.

Initial data collection involved observation of events, interviews, and analysis of available documents (including email correspondence). Formally arranged interviews lasted between 30 and 120 minutes, recorded and transcribed verbatim whenever possible. When recording was not possible or practical, extensive notes were taken and transcribed immediately thereafter. Observations encompassed most of the BTG initiatives (see Table 1), meetings of the cross-disciplinary BTG steering group and followon meetings of newly formed (or funded) project groups. Thus observations were collated from a wide range of activities in different stages of cross-disciplinary engagements. Activities and behaviours, conversations, group dynamics, and communication dynamics were at the core of the observations.

Follow-up data collection involved an online-based questionnaire and interviews with respondents who expressed their willingness to participate further. Our use of a questionnaire in the follow-up process was qualitative. Since we did not develop formal hypotheses (which would be inconsistent with our exploratory research approach), the questionnaire was employed as a means of quickly accessing information about opinion and activity in the BTG programme. Given our use of a simple questionnaire in a rather "qualitative mode" we are aware that self-selection might be an issue: participants with positive experiences being more likely to take the survey than those who did not find the experience rewarding. However, considering that our goal was to learn whether some nascent community was formed around the observed practices and whether those engaged in IDR recognize this emerging community, the approach fitted the purpose. The data gathered from a very high rate of responses (around half of those contacted) suggested a group significant and active enough to merit the label 'community', as we discuss later in our findings section. The detailed content of the questionnaire and follow-up interviews are discussed later in the paper, alongside the results.

3.3 Data analysis and writing 
There were six main phases in the initial data analysis. In the first phase, transcribed data were imported into NVivo 8 and analysed by author 1, in order to identify sections of the texts that described practices of some kind and to assign descriptive codes to them. Following the general principles of open coding, this stage was loosely informed by pre-existing reading on practice and IDR theories (c.f. Berg and Lune, 2004; Suddaby, 2006) to help to identify text that related to our central concerns. Accordingly, we applied analytic, interpretive coding.

In the second phase, the coding categories were discussed and evaluated for coherence and consistency (Anand et al., 2007). We also discussed the early data codes with a key member of the BTG program to establish whether the codes were intelligible and a reasonable description of the data. In the third phase, following principles adopted from interpretive research (Soss, 2006), by building on the first-level coding by looking for areas of conceptual overlap amongst the codes, we developed our first level structure comprising groups of codes describing particular practices.

In the fourth phase, we developed a higher level coding structure through the same comparative process that was applied earlier. We looked for conceptual overlap or similarity amongst code groups, and discussed possible connections. This led to the identification of three main groups of practices. In the fifth phase, having understood the generality of practice and community formation, we considered our next research focus: we considered how the different kinds of support action within the program enabled or constrained the development of the three groups of practices and, consequently, collaborative interdisciplinary communities. In the final phase, we proceeded with the construction of theory, a process involving writing, reflecting and reviewing (Feldman, 2004, p. 298).

Finally, we engaged in follow-up data collection. While the questionnaire data allowed us to assess the general trends and impact of BTG participation, additional interview transcripts were reviewed to identify data that helped us to assess our earlier data categories. The follow-up data allowed us to better consider the time dimension of practice and community development in the long term. 


\section{Findings: emergence of IDR practices and the development of collaborative community}

Here we report results related to our two research objectives: understanding the emergence of collaborative practices and communities; and characterising the role of support initiatives in the process. Hence we first describe three broadly sequential groups of practices, related to IDR collaborations, that we identified in our research: practices of enquiry, practices of engagement and practices of enactment. As we shall argue, these groups of practices are associated with the gradual emergence and continuation of a collaborative interdisciplinary community. Importantly, these collaborative practices were recognized as being different from the usual technical or disciplinary practices of participants. In our presentation of the three practice groups, addressed in turn below, we provide typical data quotations that are representative of many others. Afterwards we describe how these practices were related to the development of an IDR community. Finally, we consider how different types of support actions facilitated practice development.

\subsection{Collaborative IDR practices: interactions at the intersection of disciplines}

\subsubsection{Into the unknown: practices of enquiry}

The first group of practices relate to the exploratory stages of engaging with collaborative interdisciplinary work, during which many participants were unsure whether, and how, they would wish to proceed. We identified four major practices in this group.

'Risk taking' - participants engaging in IDR were ready to accept the higher risk of potential failures, the additional difficulties related to accessing funds, and even to accept that their career progress might be retarded. The magnitude of risk taking was captured by one of participants:

'My interest is very broad. It can be good and bad. (...) To get anywhere you need to become a recognized, international expert in something to get promoted. I just switched field again - and if I was shooting for professorship it would take me forever.' (Participant 14)

Furthermore, a number of participants related early engagement with IDR to 'getting out of their comfort zone', hence accepting the risks of the unknown and becoming 'immediately very inexpert 
once we're outside our comfort zone' (Participant 2-05) ${ }^{4}$. Risk taking associated with IDR can further be related to both the professional (as above) and the personal level:

'I'm probably more open to working in that [interdisciplinary] way and I realize that I can get rewards from that, personal rewards that I hadn't fully appreciated in advance of getting involved in BTG. So, it's challenged me in a way that I probably wouldn't have done. So, I've got myself out of comfort zones on a personal level.' (Participant 2-04)

'Exploring' involved both the willingness to entertain different understandings about a topic of interest in the 'home' institution and attending various events that could provide exposure to knowledge from different communities. This stimulated new understandings and an acceptance that the utility of such experiences might emerge later. For example one of the participants explained how he used one of his earlier projects to explore the potential of IDR in his work:

'This is where we can learn from multidisciplinary projects. Because it is funded it makes it much slower than working with a client. So I decided to use the extra time to learn and see how it could be done. I could do it the easy / fast way - just "architecture”. But (...) I thought let's see who can have some input.' (Participant 1)

Another participant links 'exploring' to a part of academia that has adopted narrow disciplinary specialization:

'The great joy of academia is actually exploring way beyond. So, if I meet someone at a conference I will say "so, how would that apply to..." and the answer more often or not I'll get is "I don't know, that's not my area." But, of course it's their area! They're academics, they should be thinking about broader questions about how this might apply somewhere or how does it connect.' (Participant 2-05)

Two other practices, 'seeking opportunities' and 'searching for connections', became apparent in a somewhat more systematic and planned pursuit of collaborative opportunities. Seeking opportunities is about finding groups to work with, without necessarily having a pre-defined intention about what the

\footnotetext{
4 "2-" in participant descriptors indicates data from the follow-up research.
} 
collaboration might involve. This was often the case for new participants attending BTG initiatives, as observed during the introduction sessions. As one of the participants explained:

'I went anyway - partly just out of interest and partly for strategic reasons. I was just coming to my position as a head of school for research so I planned to get myself more oriented towards the wider research activity at the university across departments and faculties. And also I realised the problem with visibility - the visibility of our research at the university that has possible consequences in the whole university. (...) Well, I learnt a lot and I felt it was important for the department to be represented.' (Participant 10)

'Searching for connections' was more teleological, as it implied that a (research) problem (or opportunity) had been arrived at and there was a purpose for which collaborators were sought. As one of the participants explained:

'You have to think, "I wonder if there is anybody who would be interested in this" and then do a search and try to track people down, then go down and visit them and say "this is what I was thinking about doing - does it interest you"? You've got to be pretty proactive about that. These things don't just happen by chance.' (Participant 22)

Hence individuals sought the benefits of the creative tension arising from combining different viewpoints and experiences through engaging with these practices, and often highlighted that these practices were different from their 'usual' (disciplinary) research practices.

Another practice, which we refer to as 'unpacking the problem and upframing' relates to adapting the way of presenting, and understanding, research problems and expertise. Individuals often decided to adopt the route of generalizing and de-contextualizing the research problem; or, in other words, upframing in order to attract potential partners and expertise from a wide range of possible collaborators. As participant 22 continues:

'How you frame the problem - it is a problem. You know the MoD [Ministry of Defence] no longer say we look for bids for an aircraft. They say we have to transport 50 people from point A to 
point B - because they want the most creative solutions. And if you can actually do that without actually creating an aircraft - that's fantastic.' (Participant 22)

Furthermore, another participant highlighted the dynamic relationship between both being able to present your own discipline in an attractive way - but also to appreciate other perspectives:

'I think the first skill is being able to communicate disciplinary knowledge and experience in a way that other disciplines can understand. With that comes an appreciation that the discourses were used, the narratives, the forms of representation on behalf of the disciplines are quite different and that we need both to be listening to others all the time and trying to translate and, at the same time, being a broker for our own discipline, to translate it into other people's languages and narratives that they would use.' (Participant 2-04)

While our conceptualisation of practices of enquiry is mostly based on the first-phase of our research, the follow-up data confirms that the development of certain enquiry-related skills and abilities did come from participating in BTG initiatives: $95 \%$ of respondents agreed that participating in BTG initiatives helped them to understand how to find and engage with researchers from other domains.

\subsubsection{Developing collaboratively: practices of engagement}

The second group - 'practices of engagement' - relate to the phase in which the group develops rapport and deploys practices that enable them to begin to resemble purposive inter-disciplinary collaborations. These practices were developed at an emerging proto-community level, and were mostly observed during recurring project group meetings as individuals co-created meaning as they engaged in collaboration. In the follow-up study we tracked the existence of practices of engagement by asking if, and how, abilities to pursue at least temporary purposive collaborations - discrete projects - were developed through participation in the BTG programme. Most participants agreed that such abilities were developed. We detail the practices involved in these abilities below.

The first of the six practices in this group, 'engaging', is concerned with investment in collaborative relationships, often beyond functional necessity or professional expectations to something more 
genuinely interpersonal and affective. One of the participants explained the role of this (more than just functional) relationship in an IDR context:

'True cross-disciplinary work is where there is synergy between the two areas and the fact that you are collaborating with somebody from other disciplines is inspiring you to see things in different perspectives and come up with new ideas in your own domain. And this is essential. Otherwise you just become a service subject that does development of systems for other disciplines and that's not the point.' (Participant 22)

While tokenism was often mentioned as a problem, there were also issues of core and periphery to consider. Emergent groups often struggled to see how different research practices, needs and expectations could be amalgamated, or what knowledge and research approaches were core to the collaborative idea. This problem was addressed through the practice of 'accommodating', ensuring that the (research) interests of all parties were met through, for example: making additional allowances in the scope of collaborative projects; actively seeking better understanding of the needs of peripheral participants; or adapting methodologies and research techniques. In some instances accommodating led to further learning and individuals adopting new perspectives and tools within their own disciplinary practices:

'So, it's then the translation of you go, you see how somebody else does something and you bring it back and you think "yeah, I could..." not necessarily adopt the whole regime but I can see where there are aspects of it that really benefit and can drive forward and make my research more robust as a consequence.' (Participant 2-07)

Accommodating needed to be balanced against the risk of over-accommodating. That is, simply being inclusive was of no utility if the (potential) collaborators could not find ways to work together productively. Thus the practices of 'investigating fit' and 'building fit' were also involved. These reflected a range of techniques adopted to develop and refine understandings between partners, especially in relation to how their tools and worldviews might be meshed together. Determination, patience and the ability to accommodate other viewpoints were often mentioned by respondents, who recognized the difficulty in combining practices, expectations and the needs of researchers from various communities. This is illustrated by one of the participants in the following quotation: 
'A lot of people think "if I just assemble the right team they'll all donate what they need to and it will work". (...) They just think "I need a geologist" so they just contact somebody and say "could you do the geology side?" and is it necessarily the best geologist? Is it necessarily the best working partner for you? (...) if you are trying to expand your research team (...), you interview them: you find out if they are interested in what you do; if you're interested in them working for you. You're finding out about each other before you take somebody on because there's something in the working relationship as well as the skillset that they can offer. And I think that in interdisciplinary research that's sometimes underestimated.' (Participant 2-07)

'Building fit' required further pro-active effort directed at improving the initial fit (where 'investigating fit' may have uncovered issues) thereby leading to more integrative collaborations. As one participant explained to others who were ready to abandon an idea:

'Because I'm pretty sure that if you go through several discussions, earlier or later you will find some nice problems. But we were working almost half a year on writing a proposal and still there is a doubt whether we can submit this proposal or not.' (Participant 33)

The suggestion of the participant above was to organize a number of seminars and meetings to build fit and ensure the projects had real value. While some participants mentioned cross-reading research papers from other disciplines, others kept actively engaged in clarifying and posing 'stupid' questions, and negotiating and compromising as the discussions progressed. One of the respondents explained his activity during this phase of the engagement in this way:

'you need to ask simple questions to people from other disciplines. If there is a presentation and a statement that I didn't understand - I want to understand it. I want to know what they mean. So I ask, I want to ask. (...) It's a part of the culture - how willing you are to get to know, to push the boundaries.' (Participant 14)

Once the boundaries of the collaborative activity began to be clarified, the collaborators were able to focus on the delivery of particular projects. Two practices concerned with this aspect were 'providing focus' and 'project tasking'. These practices were nuanced in different circumstances; sometimes 
leaning more towards direction, and sometimes leaning more towards the facilitation of the right conversations to help the project move forward - and perhaps lead to other ideas and projects. While some participants were mostly concerned with achieving the substantive purpose of the collaborative group, others displayed a range of practices that were further concerned with potentiating future engagements and the maintenance of the emerging collaborative community. Thus we found that 'providing focus' and 'project tasking' were on the boundary of practices concerned with community formation and maintenance, which we termed 'practices of enactment'.

\subsubsection{Sustaining and developing the community: practices of enactment}

Practices from this group are of particular importance to our research questions as these relate to the under-explored constitutive dynamic links between practice and community. In our study we observed significant efforts being made to ensure the sustainability of practices and community, and in this context an important issue was the development and maintenance of trust. Hence participants' attention was not just focused on what was to be done, but also on how it was to be done. A formal underpinning of trust was signified by deployment of the practice of 'maintaining procedural justice': recognizing and adequately rewarding contributions, negotiating the final outputs of collaborative projects, and intervening whenever justice was compromised. This sometimes resulted in radical action of one of two kinds, both of which supported emerging collaborative practices and helped to ensure the overall health of the emerging network. The first form of radical action involved the disengagement of either dissatisfied participants or 'unjust' partners. The second involved the dissolution of a team followed by re-assembly of smaller groups of participants who seemed more genuinely committed to the collaborative process. In this context some individuals were labelled as (for example) 'impossible to work with', or 'arrogant' and 'interested only in themselves / what they could get' out of the collaboration. But others were praised for their justness and the ability to develop trust in the competencies and expertise of the other participants, especially the more junior ones. This is illustrated by the following quotation from a participant: 
'there's always people who would want all the glory and kudos for themselves but you do get a lot of people who say "it's your turn to have this responsibility because it will be good for you."” (Participant 2-07)

Another observed practice focused on addressing these (potential) problems, and ensuring the continuation of collaborative engagements was 'nurturing', through focusing on inter-personal relationships and the development of shared understanding between particular collaborators. This involved, for example, protecting time for gradual and personal interaction with collaborators, as reflected in the following quotation:

'At initial stages people are going to give a small percentage of their effort. (...) But with that small bit of time it's easily forgotten. What you have to do, I suppose, is to make sure that it [IDR] is gaining people's $5 \%$ of research energy and that does not slip down to zero because that's going to be easy - from $5 \%$ to $0 \ldots$ But I think that's why the [collaboration] is an example of something that was small, $5 \%$, but we meet regularly, there would be a coffee, somebody would bring a cake or something. It was that small things, things that keep things going - it becomes a bit more sociable.' (Participant 16).

Going further, participants displayed the practices of 'involving others' and 'brokering connections'. These both aimed at socializing new participants and consciously extending the emergent 'collaboration-prone' network, while ensuring that the right people were being inducted and socialized. Indeed, it was important for participants to see that the new participants' practices would fit with the collaborative culture. As one participant explained his journey in 'learning the ropes' of IDR: 'For the first 6 months I was learning what BTG was - but then for the last 4-5 months it was good learning about collaborating. And now we can help others. I want to see more people getting involved in our department.' (Participant 24)

One of the reasons behind actively engaging others was the recognition of the limitations of the current network. As explained by another, seasoned, participant: 
'the problem is that people get quickly saturated - they have no more time $[\ldots]$ there are too few people like that [engaged in IDR] - the network gets easily saturated.' (Participant 14)

'Brokering connections' signified additional effort in ensuring the initial connections developed into fully functional collaborations. We observed people remaining involved in projects as 'facilitators' or 'translators' or taking a central role in the community despite only a peripheral interest in the substantive outcomes of the project. As another participant explained:

'... it's that centrality of having someone who, like a Bentham Panopticon jail, can actually see really what's going on across the university is crucial because there is actually a remarkable amount going on which overlaps, or there are connections that would be interesting and we probably need more of that, or someone with an oversight in terms of how these things connect together.' (Participant 2-05)

Furthermore, respondents linked the practice of 'brokering connections' with the ability to discern incoming inquiries having the potential for fruitful collaborations and make substantive rather than superficial connections.

\subsection{From practice to community: the emergence of IDR community}

One of the goals of the follow-up phase of the research was to revisit the question (three years after the initial phase of data collection) of whether the BTG programme had potentiated the emergence of a community of IDR practitioners. Our initial analysis had suggested that a community was emerging, and in the follow-up research we sought to determine whether we could be more confident in our claim that a community had indeed developed. Table 3 presents a summary of the relevant questionnaire findings, followed by further elaboration of material from the follow-up interviews.

Table 3

Summary of the survey findings

\begin{tabular}{|l|c|c|}
\hline Questionnaire prompt & $\begin{array}{c}\text { Number of } \\
\text { responses }\end{array}$ & $\begin{array}{c}\text { \% of } \\
\text { responses }\end{array}$ \\
\hline $\begin{array}{l}\text { I believe there is an informal group of researchers who will continue to develop IDR projects } \\
\text { and ideas even after the BTG programme ends }\end{array}$ & 1 & $2 \%$ \\
\hline I don't think so & 3 & $6 \%$ \\
\hline Not really - except for some sporadic cases & 21 & $41 \%$ \\
\hline Probably a few people would &
\end{tabular}




\begin{tabular}{|c|c|c|}
\hline There definitely is such a group & 26 & $51 \%$ \\
\hline \multicolumn{3}{|c|}{$\begin{array}{l}\text { Participating in BTG initiatives and other IDR projects helped me to identify researchers in } \\
\text { other departments that I consider particularly good at doing IDR projects }\end{array}$} \\
\hline Not at all & 5 & $9 \%$ \\
\hline Identified some people but not sure they have any particular IDR skills & 16 & $30 \%$ \\
\hline Identified quite a few and I think they are good at IDR & 20 & $37 \%$ \\
\hline Yes and these people definitely are really good at IDR & 13 & $24 \%$ \\
\hline \multicolumn{3}{|c|}{$\begin{array}{l}\text { After participating in BTG initiatives (or other IDR projects) I believe it is important to engage } \\
\text { others (colleagues, PhD students) to develop this capability across the university }\end{array}$} \\
\hline Not at all Important & 0 & $0 \%$ \\
\hline Only marginally important to the success of IDR & 4 & $7 \%$ \\
\hline Important, but not crucial to the success of IDR & 15 & $28 \%$ \\
\hline Very important to keep IDR going & 35 & $65 \%$ \\
\hline \multicolumn{3}{|c|}{$\begin{array}{l}\text { After participating in BTG, and other IDR initiatives, I feel I know who to approach in other } \\
\text { departments to discuss IDR ideas }\end{array}$} \\
\hline Not at all - still would not know who to approach & 2 & $4 \%$ \\
\hline I met a few of people that I could possibly approach & 17 & $33 \%$ \\
\hline It helped me to find a number of people I could approach & 22 & $43 \%$ \\
\hline Yes, it definitely helped me to find the right people I can approach & 10 & $20 \%$ \\
\hline
\end{tabular}

The majority of respondents indicated that some form of enduring (IDR) community existed and they could identify the right people across the university with whom to pursue their IDR ideas. Most respondents also showed an awareness of the need to actively engage new members in IDR practices. Indeed, the majority of respondents indicated that they would encourage their colleagues to get involved in BTG initiatives in the future. To some extent, this shows one of the typical characteristics and purposes of a $\mathrm{CoP}$ - providing socialized learning and development for apprentices (c.f. Lave and Wenger, 1991). Furthermore, there was also a recognized cadre of 'masters', which is also typical of CoPs. As one of the follow-up interviewees explained:

'I think there is a network of people in this university who are good at IDR. I think there are two reasons for that. One is that IDR has become a pretty major feature of the way the university works, or proposes to work. The second aspect of that, in terms of our consciousness, (...) would be that there was a proposal, certainly two years ago, that all students in their studies would take an IDR element [of their study].' (Participant 2-05, emphasis added) 
Although a number of respondents recognized the role of some formal structures and initiatives in facilitating IDR and the emergence of this community, others made a distinction between the 'formal project' groups and the informal IDR community, as illustrated in the following explanation: 'some of them [IDR networks] are structured. (...) But I think most of them, however, rely on key partners - key individuals, stakeholders - to keep the conversations going beyond any formal structure. So, it's more [of an] implicit rather than an explicit structure in place for it and again that works best for interdisciplinary research.' (Participant 2-04)

Other respondents similarly saw it as more of an informal, less structured community.

When trying to define the key characteristics of the IDR community, most of the respondents mentioned some kind of attitude towards this form of research. For example, one of the participants found 'a disposition amongst people, regardless of discipline, to be curious' as the 'most important guiding principle' when looking for IDR partners (Participant 2-05). However, curiosity alone was not enough, as he/she explained that with 'some of the people who were there I just didn't gel with at all and I couldn't work with'. This 'gelling' is closely linked to some of the practices we identified earlier, as can be seen in the following example:

'I didn't find their [previous IDR partners] approach to an open discussion very helpful. I tended to be told "this is what needs to be done." I was then advised of someone [elsewhere] who would be a very interesting, very argumentative - in a good sense - individual who' $d$ be interested in a much more open debate, maybe, and they then suggested a couple of people come along. That proved a very interesting experience.' (Participant 2-05)

Finally, another participant defined this as a 'matter of both personality and experience' (Participant 206). In terms of the practices being carried out by the emerging community and beyond the BTG projects, the following example illustrates the dynamics of the organic development of the community:

'Before you came today I was thinking I'll have a look at my BTG list. 25 colleagues, across the university, in BTG projects. 14 of them I have worked with since on projects of the 25 and 3 of them I have worked with on at least three projects. But not all of them and some of them I probably 
wouldn't work with again. You know, we did a project and that was fine but we probably wouldn't get along with it, nobody got enough out of it, beyond what we wanted to do. But, that's what interdisciplinary work is about. That sort of return, it seems to me, is quite good. If half the relationship has a second stage and even only one in seven, or one in eight continuing through beyond it but if you get to a second or third (...) project, you don't need many of them across the institution to realize that you actually constructed a sort of network.' (Participant 2-04, emphasis added)

As the above discussion illustrates, the project potentiated not only the emergence of collaborative practices, but also a growing community. Furthermore, practices of enactment can be associated with the long-term sustainability and health of the community.

In the following section we turn our attention to the different BTG initiatives and how these supported the development of IDR practices in general.

\subsection{Support for the development of IDR practices and collaborative community}

BTG interventions consisted of an array of events designed to facilitate interdisciplinary interaction in a variety of ways, as described earlier in Table 1. The various BTG support interventions differed significantly in relation to potentiating the development of the three groups of IDR practices, and through that process the establishment of a collaborative IDR community. Furthermore, some of the initiatives complemented or supported each other (in some cases by design - e.g. sandpits offered funding for follow-on proposal groups). Table 4 provides a brief summary of how each of the support actions potentiated the development of IDR practices. This table omits function-related meetings, which had no discernible impact on the development of these practices.

Table 4

Support actions and practice development potential

\begin{tabular}{|l|l|}
\hline $\begin{array}{l}\text { Support intervention } \\
\text { and key characteristics }\end{array}$ & $\begin{array}{l}\text { Summary evaluation - in terms of the potential to support the } \\
\text { development of practices of enquiry, engagement or enactment }\end{array}$ \\
\hline
\end{tabular}




\begin{tabular}{|c|c|}
\hline $\begin{array}{l}\text { University research day } \\
\text { Institution-wide poster } \\
\text { conference open to all, } \\
\text { with prizes for IDR ideas. }\end{array}$ & $\begin{array}{l}\text { This event provided some opportunities for practices of enquiry to be } \\
\text { developed and deployed, but was essentially concerned with raising } \\
\text { awareness of university research and the BTG programme - a function it } \\
\text { performed well. }\end{array}$ \\
\hline $\begin{array}{l}\text { Speed networking } \\
\text { Networking meetings } \\
\text { involving multiple paired } \\
\text { conversations with } \\
\text { possible collaborators. }\end{array}$ & $\begin{array}{l}\text { This initiative was well suited to support the practices of enquiry and } \\
\text { engagement. The initiative provided opportunities for exploring, seeking } \\
\text { opportunities and searching for connections while also providing a } \\
\text { platform for building fit, although limited, and involving others. For } \\
\text { some participants speed networking was the first step towards the stage } \\
\text { of risk taking associated with IDR. }\end{array}$ \\
\hline $\begin{array}{l}\text { New joiners meeting } \\
\text { Similar to speed } \\
\text { networking, but with a } \\
\text { focus on allowing new } \\
\text { researchers to become } \\
\text { involved. }\end{array}$ & $\begin{array}{l}\text { These simple events were effectively oriented towards practices of } \\
\text { enquiry (although not named as such in the events) and were useful for } \\
\text { that purpose. We suggest that they would also have a role in the ongoing } \\
\text { "socialization of apprentices" that would maintain the community in the } \\
\text { long term. As a spin off, there were some serendipitous connections that } \\
\text { began to move towards project-oriented practices of engagement, but as } \\
\text { expected there was no evidence in these contexts of the practices of } \\
\text { enactment (which we would expect to take place elsewhere). }\end{array}$ \\
\hline $\begin{array}{l}\text { Themed seminars } \\
\text { A series of semi-formal, } \\
\text { researcher-led } \\
\text { discussions on a broad } \\
\text { theme. }\end{array}$ & $\begin{array}{l}\text { This initiative was particularly strong in encouraging early-stage } \\
\text { practices of enquiry. This is because these events were designed to allow } \\
\text { researchers to offer their own themes for discussion and exploration, and } \\
\text { were relatively broad in their focus. For this reason, practices of } \\
\text { engagement and enactment were also less evident, since these were } \\
\text { associated with more focused discussions connected to concrete projects } \\
\text { - which took place in other events and settings. }\end{array}$ \\
\hline $\begin{array}{l}\text { Sandpits } \\
\text { One-off but extensive (1.5 } \\
\text { day), facilitated process } \\
\text { events at which research } \\
\text { themes could be hewn } \\
\text { into outline research } \\
\text { problems and potential } \\
\text { collaborative projects. }\end{array}$ & $\begin{array}{l}\text { These events were similar in some ways to the themed seminars in } \\
\text { having a researcher-led focus on particular themes. But because these } \\
\text { themes were problem-oriented, the development and deployment of } \\
\text { project-oriented practices of engagement was more evident. This meant } \\
\text { that the initial practices of enquiry needed to have been undertaken } \\
\text { elsewhere. This was not always the case, as some 'falling out' between } \\
\text { possible partners indicated. There had not been sufficient opportunity to } \\
\text { properly explore individual-level opportunities and risks associated with } \\
\text { potential collaborators in an enquiry stage, and progress towards } \\
\text { practices of engagement was strong - but sometimes premature. The } \\
\text { evidence for practices of enactment following these events is unclear (we } \\
\text { would expect those to be evident in other contexts) but given the mixed } \\
\text { patterns of success we would expect this process to lead to some shaping } \\
\text { of boundaries between those who might be welcome in communities - } \\
\text { and those who were likely to be excluded. }\end{array}$ \\
\hline $\begin{array}{l}\text { Themed workshops } \\
\text { Relatively unstructured, } \\
\text { but long term and } \\
\text { iterative processes of } \\
\text { interaction involving } \\
\text { parties expressing interest } \\
\text { in a theme. }\end{array}$ & $\begin{array}{l}\text { Themed workshops were particularly important for practices of } \\
\text { engagement and enactment, though the initiative also provided platform } \\
\text { for practices of enquiry. Prolonged engagements supported development } \\
\text { of practices of investigating and building fit, as well as accommodating. } \\
\text { These workshops often lead to further projects, leading to involving } \\
\text { others as well as sustaining the emerging community through } \\
\text { deployment of practices of procedural justice. }\end{array}$ \\
\hline $\begin{array}{l}\text { Follow-on funding } \\
\text { A mechanism to allow } \\
\text { established (early-stage) } \\
\text { project groups to continue } \\
\text { to develop their } \\
\text { collaborative endeavours. }\end{array}$ & $\begin{array}{l}\text { This mechanism was deliberately targeted towards collaborations with } \\
\text { existing clear project ideas and long-term potential. Our contact with } \\
\text { these groups in their collaborative sessions was limited. But individual } \\
\text { recipients of this support featured strongly in our data set related to } \\
\text { practices of engagement and enactment, and for this reason we see this } \\
\text { mechanism as providing strong support for those practices. }\end{array}$ \\
\hline
\end{tabular}




\begin{tabular}{|l|l|}
\hline $\begin{array}{l}\text { Dragons' den } \\
\text { A high-profile } \\
\text { competition for IDR } \\
\text { project teams with ideas, } \\
\text { but with significant "seed } \\
\text { funding" for the winners. }\end{array}$ & $\begin{array}{l}\text { This event provided some opportunities for late stage practices of } \\
\text { engagement to be developed and deployed, as participants needed to } \\
\text { form coherent project teams to compete for significant internal funding. }\end{array}$ \\
$\begin{array}{l}\text { This event provide any evidence for the earlier phase of } \\
\text { develont (enquiry), as one would expect. However, it also fulfilled an } \\
\text { away and excitement raising purpose within the programme, which } \\
\text { may possibly be an encouragement for others to "get involved". } \\
\text { For the funded groups the mechanisms supported development of some } \\
\text { of the practices of enactment (similarly to follow-on funding). }\end{array}$ \\
\hline
\end{tabular}

Space does not allow us to explore these further. It is essential to note that there were important, supportive relationships between interventions that often helped to maximize the development of practices and community. In general, it seems that the multitude of opportunities to develop practices of enquiry were helpful in potentiating commitment to larger or longer events, where the costs of commitment were commensurately more substantial too.

\section{Discussion and conclusions}

In this part of the paper we develop the theoretical and practical insights arising from our study. After presenting these we consider the limitations, further research and summarise our contribution in our concluding remarks. To begin, we summarize our findings in Figure 1 and discuss the elements of the figure in the sections that follow below.

\section{Figure 1}

Practices at the interface of interacting communities: emergence, levels of practicing and impact of support interventions 


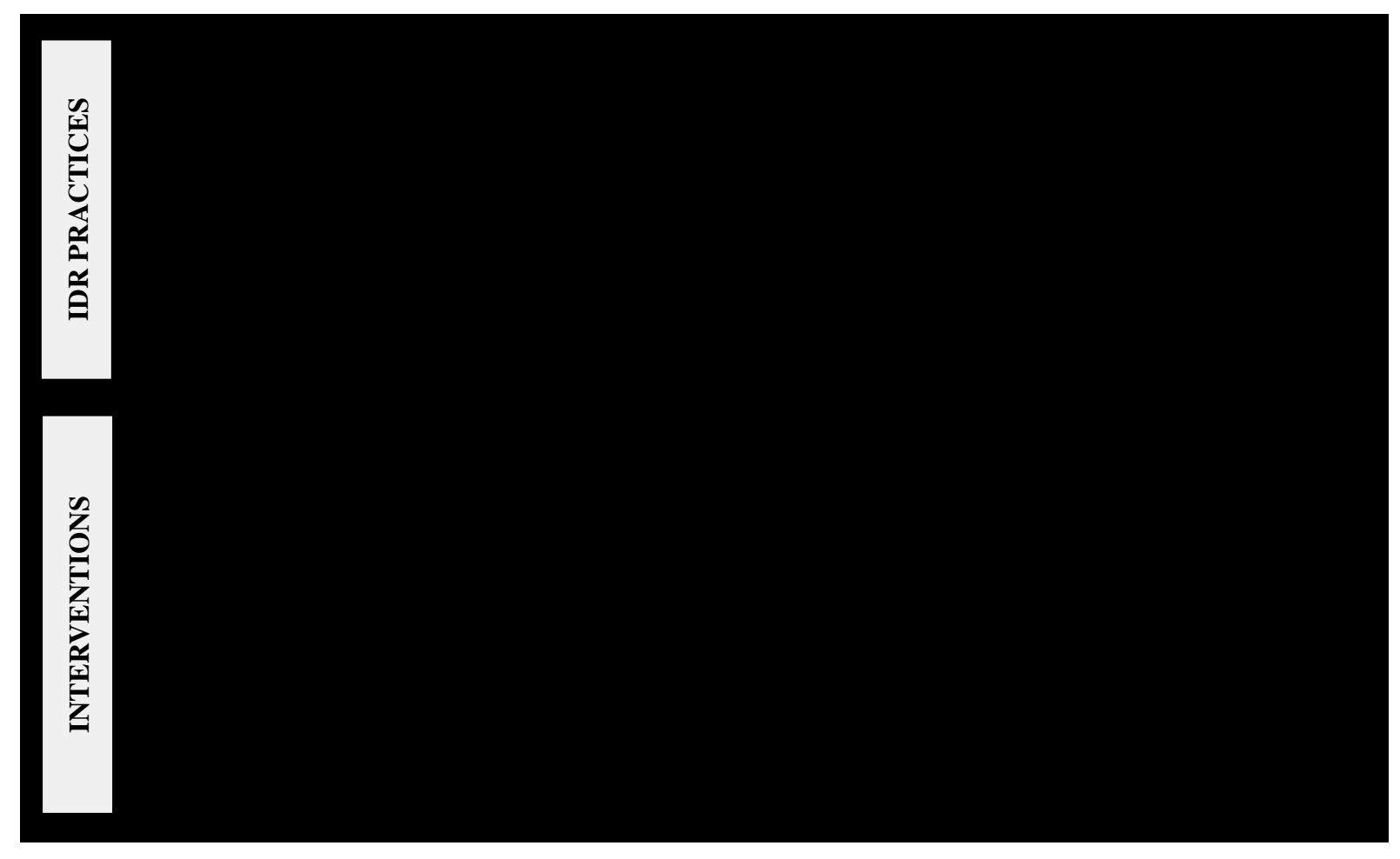

\subsection{Practices at the interface of interacting communities}

The first area of our contribution is concerned with the dynamics of emergence of IDR practices and development of a community endorsing and maintaining these practices. First, our results demonstrate three groups of practices that emerge in IDR communities of practice: practices of enquiry,

engagement and enactment. Furthermore, the three groups of IDR practices provide for stability and permanence beyond the specifics of observed IDR projects. Hence we differ from those who have argued that practices do not outlive specific projects (Ferlie et al., 2005; Lindkvist, 2005; Scarbrough and Swan, 2008). We also provide insights on how collaborative interdisciplinary work is accomplished in organizations in a repeatable and durable manner (e.g. see Engeström, 2005; König et al., 2013).

Our findings also reveal differences in patterns of practicing and suggest that developing IDR 'from scratch' involves practicing at two levels: 'practicing individually' and 'practicing together'. We found practices of enquiry to echo the meaning-making articulated by Nicolini (2011), and also that these practices can be characterized as individual achievements that are difficult to ascribe to a 
community. Individuals developed and deployed practices of enquiry to engage in conversations with other disciplines, to find shared interests and to initiate development of shared understandings. In some respects this kind of 'practicing individually' can be seen as a form of legitimate peripheral participation (Lave and Wenger, 1991) where individuals experiment by adapting their 'regular' practices to fit new contexts (Bruns, 2013). But interestingly it is peripheral without having reference to a defined social 'centre': an established community context for the meaningfulness of such practices did not exist at the outset of our study. This is different from what we might expect from the literature, where the existence of a community is generally presumed (Haythornthwaite, 2006; Lyall and Meagher, 2012). This presumption holds even when authors are clear that this community is nevertheless realized through practice; they still assume that some stable social structure is necessary for the maintenance and development of practices (see Bjørkeng et al., 2009; Gherardi, 2009b).

While there is a degree of independent practicing in the enquiry phase, practicing becomes associated with an emerging proto-community in engagement and enactment. Practices of engagement and enactment enabled collaboration through the negotiation of norms and expectations inscribed in crystallized practices (Bjørkeng et al., 2009), and thus allowed for 'practicing together' among an informal community of like-minded practitioners. This adds to treatments of learning and community formation discussed in the literature on CoPs (Elkjaer, 2003, p. 39; Lave, 2008; Yakhlef, 2010).

However, it was possible for projects to be completed through deploying techniques of project management in cross-disciplinary collaborations (e.g. see König et al., 2013). Hence the formation of an enduring community is not inevitable, since the practices of engagement and enactment might be constrained by project management goals and not leave any lasting legacy (Ferlie et al., 2005; Scarbrough and Swan, 2008). Thus we understand why those who focus their research on particular projects would arrive at the conclusion that enduring communities do not form (Lindkvist, 2005). What is nevertheless missed in this view is the potential for projects to lead to the development of practices that could be utilized in future collaborations. That is, practices that are developed and knowledge that is acquired in those projects could be transferred to future collaborative engagements 
(see Hibbert and Huxham, 2005). At the minimum, there is thus potential for communities to (re)form later. At the maximum, communities are able to form alongside the delivery of initial project(s).

\subsection{Interventions to support the development of IDR practices}

Although we show that collaborative practices can potentiate the maintenance and development of collaborative communities, we also identified actions that facilitated the emergence of particular IDR practices. This is important for informing future initiatives promoting interdisciplinary collaboration and in guiding the operationalization of IDR for policy purposes (Huutoniemi et al., 2010; see also Katz and Martin, 1997; Siedlok and Hibbert, 2014). Rather than focusing on distinguishing between different levels of disciplinary integration (Huutoniemi et al., 2010; Petts et al., 2008), approaching IDR processes as being accomplished through a set of practices provides more useful levers for policy makers. That is, supporting the development of practices is a better way to support the necessary development for IDR collaborations to be fruitful in the long term (Jeffrey, 2003; Lattuca, 2002, pp. 160-161). Moreover, we found that different types of events support the development of different types of practices, but there is an order of development. Thus an appropriate mix of interventions is important, as is the sequence in which they are deployed. There should first be several low-risk opportunities for the development of practices of enquiry. This phase is pivotal in identifying perhaps to participants themselves - those who are 'comfortable with this kind of discomfort', before any extensive commitment is required. This means that events like 'speed networking' are an invaluable and economical way of establishing who is interested in developing their 'taste' (Gherardi, 2009a) for a prospective IDR community. Other support interventions, which potentiate all three phases - such as 'themed workshops' - can then be rolled out with more confidence to support the development of future collaborative communities. As the summary in Table 4 suggests, an appropriate mix of events can also be important in promoting the idea of IDR (and thereby 'recruiting participants') as well as supporting the development of collaborative communities.

5.3 Concluding remarks: limitations, further research and summary of contribution 
While we have confidence in applying our insights to the development of similar initiatives in the university research sector and more tentatively beyond, we need to acknowledge the key limitation of this study: our insights are based on data from a specific organizational context, a research-intensive university in the UK. For this reason, we would like to see further studies in university-industry and industrial research collaborations to confirm the broader generalizability of our findings, in a range of other national and international contexts. Additionally, we also see a need to investigate two related questions that could not be addressed within the limits of this study. First, how might practices be imported and adapted between contexts? This focus might be fruitful ground for those taking an organizational learning perspective on IDR processes. Second, how do barriers to IDR operate dynamically, in tension with the positive support factors that we have addressed, on the environment of IDR collaborations? This approach would yield a broader understanding of patterns of success and failure and represents an opportunity for those looking through an institutional theory lens.

Nevertheless, we provide some important insights through our research. The observed distinction between practicing at individual (enquiry) and proto-community (engagement and enactment) levels adds to research on practices and communities (Gherardi, 2009b; Nicolini, 2009). It illuminates the process of renewal of communities (Geiger, 2009), and the patterns of order-producing within them (Nicolini, 2009). Overall, we support arguments that suggest it is the development of practice that precedes, and potentiates, the emergence of a community - linking to the focus suggested by Gherardi (2009a, p. 121) on the 'practices of community'. Furthermore, we have indicated how IDR practices emerge in the absence of an established community, and the relationship of support interventions to the formation of such practices.

These insights have a number of practical implications, two of which we wish to highlight here. First, our findings provide an additional conceptualization of collaborative IDR processes, providing policymakers and university administrators with a better understanding of how IDR can be potentiated and sustained across research-led organizations. These insights may apply to both academic and nonacademic settings, as some of the general dynamics can be applied in other contexts where collaboration between different knowledge domains is necessary. Second, the findings provide 
interested practitioners with some clues about the potential impact of different support interventions

on the development of IDR practices and, subsequently, successful collaborations. We suggest that

future initiatives should focus on supporting the development of collaborative practices - and,

consequently, addressing the problems that inhibit the collaborative IDR process in the long term.

\section{References}

Adler, P., Heckscher, C., 2006. Towards collaborative community, in: Heckscher, C., Adler, P. (Eds.), The Firm as a Collaborative Community: Reconstructing Trust in the Knowledge Economy. Oxford University Press, Oxford, pp. 1-105.

Adler, P., Kwon, S.-W., Heckscher, C., 2008. Perspective - Professional Work: The Emergence of Collaborative Community. Organization Science 19, 359-376.

Alvesson, M., Deetz, S., 2000. Doing critical management research. Sage Publications Limited, London.

Amin, A., Roberts, J., 2008. The resurgence of community in economic thought and practice, in: Amin, A., Roberts, J. (Eds.), Community, Economic Creativity, and Organization. Oxford University Press, Oxford, pp. 11-36.

Anand, N., Gardner, H., Morris, T., 2007. Knowledge-Based Innovation: Emergence and Embedding of New Practice Areas in Management Consulting Firms. Academy of Management Journal 50, 406-428.

Aram, J.D., 2004. Concepts of interdisciplinarity: Configurations of knowledge and action. Human Relations 57, 379-412.

Becher, T., Trowler, P.R., 1989. Academic tribes and territories. Open University Press, Milton Keynes, UK.

Berg, B.L., Lune, H., 2004. Qualitative research methods for the social sciences.

Bjørkeng, K., Clegg, S., Pitsis, T., 2009. Becoming (a) practice. Management Learning 40, 145-159.

Blackler, F., Regan, S., 2009. Intentionality, agency, change: Practice theory and management. Management Learning 40, 161-176.

Boden, D., Borrego, M., Newswander, L.K., 2011. Student socialization in interdisciplinary doctoral education. High Educ 62, 741-755. doi:10.1007/s10734-011-9415-1

Brown, J.S., Duguid, P., 1991. Organizational Learning and Communities-of-Practice: Toward a Unified View of Working, Learning, and Innovation. Organization Science 2, 40-57. doi:10.1287/orsc.2.1.40

Brown, J.S., Duguid, P., 2001. Knowledge and organization: a social practice perspective. Organ Sci $12,198-213$.

Buanes, A., Jentoft, S., 2009. Building bridges: Institutional perspectives on interdisciplinarity. Futures 41, 446-454.

Carlile, P., 2002. A Pragmatic View of Knowledge and Boundaries: Boundary Objects in New Product Development. Organization Science 13, 442-455. doi:10.1287/orsc.13.4.442.2953

Cox, A., 2005. What are communities of practice? A comparative review of four seminal works. Journal of Information Science 31, 527-540. doi:10.1177/0165551505057016

Czarniawska, B., 2004. On time, space, and action nets. Organization 11, 773-791.

Dougherty, D., 1992. Interpretive barriers to successful product innovation in large firms. Organization Science 3, 179-202.

Duguid, P., 2005. "The Art of Knowing": Social and Tacit Dimensions of Knowledge and the Limits of the Community of Practice. The Information Society 21, 109-118. doi:10.1080/01972240590925311

Duncker, E., 2001. Symbolic communication in multidisciplinary cooperations. Science, Technology \& Human Values 26, 349-386. 
Elkjaer, B., 2003. Social learning theory: Learning as participation in social processes. The Blackwell handbook of organizational learning and knowledge management 38-53.

Engeström, Y., 2005. Knotworking to create collaborative intentionality capital in fluid organizational fields. Advances in Interdisciplinary Studies of Work Teams 11, 307-336.

Engeström, Y., 2006. From well-bounded ethnographies to intervening in mycorrhizae activities. Organization Studies 27, 1783-1793.

Feldman, M.S., 2004. Resources in emerging structures and processes of change. Organization Science 15, 295-309.

Ferlie, E., Fitzgerald, L., Wood, M., Hawkins, C., 2005. The nonspread of innovations: the mediating role of professionals. Academy of Management Journal 48, 117-134.

Finkenthal, M., 2001. Interdisciplinarity: Toward the Definition of a Metadiscipline?, American University Studies. Peter Lang Publishing, New York.

Freeman, J.H., Audia, P.G., 2006. Community Ecology and the Sociology of Organizations. Annual Review of Sociology 32, 145-169.

Geiger, D., 2009. Revisiting the concept of practice: toward an argumentative understanding of practicing. Management Learning 40, 129-144.

Gertler, M.S., 2008. Buzz without being there? Community of Practice in context., in: Roberts, J., Amin, A. (Eds.), Community, Economic Creativity, and Organization. Oxford University Press, Oxford, pp. 203-226.

Gherardi, S., 2009a. Introduction: The Critical Power of the Practice Lens. Management Learning 40, $115-128$.

Gherardi, S., 2009b. Practice? It's a matter of taste! Management Learning 40, 535-550.

Gooch, J.C., 2005. The dynamics and challenges of interdisciplinary collaboration: a case study of Cortical depth of Bench in group proposal writing. Professional Communication, IEEE Transactions on 48, 177-190.

Haas, M.R., Park, S., 2010. To share or not to share? Professional norms, reference groups, and information withholding among life scientists. Organization Science 21, 873-891.

Handley, K., Sturdy, A., Fincham, R., Clark, T., 2006. Within and beyond communities of practice: making sense of learning through participation, identity and practice. Journal of Management Studies 43, 641-653.

Haythornthwaite, C., 2006. Learning and knowledge networks in interdisciplinary collaborations. Journal of the American Society for Information Science and Technology 57, 1079-1092.

Hibbert, P., Huxham, C., 2005. A little about the mystery: Process learning as collaboration evolves. European Management Review 2, 59-69.

Huutoniemi, K., Klein, J.T., Bruun, H., Hukkinen, J., 2010. Analyzing interdisciplinarity: Typology and indicators. Research Policy 39, 79-88.

Jamali, H.R., Nicholas, D., 2010. Interdisciplinarity and the information-seeking behavior of scientists. Information processing \& management 46, 233-243.

Jeffrey, P., 2003. Smoothing the waters. Social Studies of Science 33, 539-562.

Katz, J.S., Martin, B.R., 1997. What is research collaboration? Research policy 26, 1-18.

Kellogg, K.C., 2011. Hot lights and cold steel: Cultural and political toolkits for practice change in surgery. Organization Science 22, 482-502.

Khapova, S.N., Arthur, M.B., 2011. Interdisciplinary approaches to contemporary career studies. Human Relations 64, 3-17.

Kirkman, B.L., Cordery, J.L., Mathieu, J., Rosen, B., Kukenberger, M., 2013. Global organizational communities of practice: The effects of nationality diversity, psychological safety, and media richness on community performance. Human Relations 66, 333-362. doi:10.1177/0018726712464076

Klein, J.T., 1990. Interdisciplinarity: History, Theory, and Practice. Wayne State University Press, Detroit, Michigan.

König, B., Diehl, K., Tscherning, K., Helming, K., 2013. A framework for structuring interdisciplinary research management. Research Policy 42, 261-272.

Lattuca, L.R., 2002. Learning interdisciplinarity: sociocultural perspectives on academic work. Journal of Higher Education 73, 711-739. 
Lave, J., 2008. Epilogue: Situated learning and changing practice, in: Amin, A., Roberts, J. (Eds.), Community, Economic Creativity, and Organization. Oxford University Press, Oxford, pp. 283303.

Lave, J., Wenger, E., 1991. Situated Learning: Legitimate Peripheral Participation. Cambridge University Press, Cambridge, UK.

Lawrence, B.S., Després, C., 2004. Futures of transdisciplinarity. Futures 36, 397-405.

Lawrence, T.B., Hardy, C., Phillips, N., 2002. Institutional Effects of Interorganizational Collaboration: The Emergence of Proto-Institutions. The Academy of Management Journal 45, 281-290. doi:10.2307/3069297

Liedtka, J., 1999. Linking Competitive Advantage with Communities of Practice. Journal of Management Inquiry 8, 5-16. doi:10.1177/105649269981002

Lindkvist, L., 2005. Knowledge communities and knowledge collectivities: a typology of knowledge work in groups. Journal of Management Studies 42, 1189-1210.

Lyall, C., Meagher, L., 2012. A masterclass in interdisciplinarity: research into practice in training the next generation of interdisciplinary researchers. Futures 44, 608-617.

Martin, B.R., 2011. What can bibliometrics tell us about changes in the mode of knowledge production? Prometheus 29, 455-479.

Miettinen, R., Samra-Fredericks, D., Yanow, D., 2009. Re-turn to practice: an introductory essay. Organization Studies 30, 1309-1327.

Morlacchi, P., Martin, B.R., 2009. Emerging challenges for science, technology and innovation policy research: A reflexive overview. Research Policy 38, 571-582. doi:10.1016/j.respol.2009.01.021

Nicolini, D., 2009. Zooming in and out: Studying practices by switching theoretical lenses and trailing connections. Organization Studies 30, 1391-1418.

Nicolini, D., 2011. Practice as the Site of Knowing: Insights from the Field of Telemedicine. Organization Science 22, 602-620.

Nicolini, D., Mengis, J., Swan, J., 2012. Understanding the role of objects in cross-disciplinary collaboration. Organization Science 23, 612-629.

Nooteboom, B., 2008. Cognitive distance in and between Communities of Practice and firms: Where do exploitation and exploration take place, and how are they connected?, in: Amin, A., Roberts, J. (Eds.), Community, Economic Creativity, and Organization: Community, Economic Creativity, and Organization. Oxford University Press, Oxford, pp. 123-147.

O’Mahony, S., Bechky, B.A., 2008. Boundary organizations: Enabling collaboration among unexpected allies. Administrative Science Quarterly 53, 422-459.

Olsen, D.S., 2009. Emerging interdisciplinary practice: making nanoreactors. The Learning Organization 16, 398-408.

Palmer, C.L., 1999. Structures and strategies of interdisciplinary science. Journal of the American Society for Information Science 50, 242-253. doi:10.1002/(SICI)1097-4571(1999)50:3<242::AIDASI7> 3.0.CO;2-7

Petts, J., Owens, S., Bulkeley, H., 2008. Crossing boundaries: Interdisciplinarity in the context of urban environments. Geoforum 39, 593-601.

Pickett, S., Burch Jr, W.R., Grove, J.M., 1999. Interdisciplinary research: maintaining the constructive impulse in a culture of criticism. Ecosystems 2, 302-307.

Raasch, C., Lee, V., Spaeth, S., Herstatt, C., 2013. The rise and fall of interdisciplinary research: The case of open source innovation. Research Policy 42, 1138-1151. doi:10.1016/j.respol.2013.01.010

Roberts, J., 2006. Limits to Communities of Practice. Journal of Management Studies 43, 623-639. doi:10.1111/j.1467-6486.2006.00618.x

Rosen, M., 2007. Coming to terms with the field: understanding and doing organizational ethnography. Journal of Management Studies 28, 1-24.

Sapsed, J., Salter, A., 2004. Postcards from the Edge: Local Communities, Global Programs and Boundary Objects. Organization Studies 25, 1515-1534. doi:10.1177/0170840604047998

Scarbrough, H., Swan, J., 2008. Project work as a locus of learning: The journey through practice., in: Amin, A., Roberts, J. (Eds.), Community, Economic Creativity, and Organization. Oxford University Press, Oxford, pp. 148-178.

Schenkel, A., Teigland, R., 2008. Improved organizational performance through communities of practice. Journal of Knowledge Management 12, 106-118. doi:10.1108/13673270810852421 
Siedlok, F., Hibbert, P., 2014. The organization of interdisciplinary research: modes drivers and barriers. International Journal of Management Reviews 16, 194-210. doi:10.1111/ijmr.12016

Soss, D., 2006. Talking our way to meaningful explanations: A practice-centred view of interviewing for interpretive research., in: Yanow, D., Schwartz-Shea, P. (Eds.), Interpretation and Method: Empirical Research Methods and the Interpretive Turn. ME Sharpe Inc, New York, pp. 127-149.

Stokols, D., Hall, K., Moser, R., Feng, A., Mira, S., Taylor, B., 2012. Cross-Disciplinary Team Science Initiatives: Research , Training, and Translation., in: Frodeman, R., Klein, J.T., Mitcham, C. (Eds.), The Oxford Handbook of Interdisciplinarity. Oxford University Press, Oxford, pp. 471493.

Suddaby, R., 2006. From the editors: What grounded theory is not. Academy of Management Journal 49, 633-642.

Szostak, R., 2007. How and why to teach interdisciplinary research practice. Journal of Research Practice 3, Article M17.

Thompson, M., Walshmam, G., 2009. Organizational Communities of Practice: wrong fork in the road? Presented at the 23rd Colloquium fo European Group for Organizational Studies, Barcelona, Spain.

Van Rijnsoever, F.J., Hessels, L.K., 2011. Factors associated with disciplinary and interdisciplinary research collaboration. Research Policy 40, 463-472. doi:10.1016/j.respol.2010.11.001

Weingart, P., Stehr, N., 2000. Practising interdisciplinarity. University of Toronto Press, Toronto.

Welsh, E., Jirotka, M., Gavaghan, D., 2006. Post-genomic science: cross-disciplinary and large-scale collaborative research and its organizational and technological challenges for the scientific research process. Philosophical Transactions of the Royal Society A: Mathematical, Physical and Engineering Sciences 364, 1533-1549.

Wenger, E., 1998. Communities of Practice: Learning, Meaning, and Identity, 1st ed. Cambridge University Press.

Wenger, E., 2000. Communities of Practice and Social Learning Systems. Organization 7, 225-246. doi: $10.1177 / 135050840072002$

Wenger, E., McDermott, R.A., Snyder, W., 2002. Cultivating communities of practice: A guide to managing knowledge. Harvard Business Press, Cambridge, MA.

Yakhlef, A., 2010. The three facets of knowledge: A critique of the practice-based learning theory. Research Policy 39, 39-46.

Ynalvez, M.A., Shrum, W.M., 2009. International graduate science training and scientific collaboration. International Sociology 24, 870-901. 